\title{
3. 'It would be good to know where our food goes': Information Equals Power?
}

\author{
Jen Cleary
}

\section{Introduction}

Wild or 'bush' ${ }^{1}$ harvest of native desert species for consumption and customary trade has been actively pursued by Aboriginal peoples in central Australia for thousands of years. ${ }^{2}$ Bush harvest for financial return has, by contrast, been occurring in central Australia for at least thirty to forty years ${ }^{3}$ and is primarily undertaken by Aboriginal women in remote settlements. ${ }^{4}$ However, to date, financial returns for these industry participants have been marginal. Harvesters have relied on the activities of non-Aboriginal traders (as they are known) ${ }^{5}$ making buying trips to their communities, and this occurs in an ad hoc fashion, with little planning or advance notice. ${ }^{6}$ This has created a situation where the women are entirely reliant on the traders in several ways: for market information, including the dynamics of product demand and in determining prices; and as sole buyers of their produce, which occurs via cash payments. ${ }^{7}$ The women have stated that they are often unsure about what the traders will require from year to year, and have found that on some occasions they have harvested particular fruits and seeds only to find that there was no demand for them. ${ }^{8}$ Added complexities include the harvesters' physical isolation from the market and a lack of transport and telecommunications - a common issue in remote Australia. ${ }^{9}$

\footnotetext{
1 Aboriginal harvesters in central Australia with whom the Desert Knowledge CRC has worked prefer the terms 'bush harvest' and 'bush food' when referring to native plants and their harvest, rather than 'wild harvest' or 'wild food', both of which infer that the plants are not cared for. M Ryder et al,'Sustainable Bush Produce Systems: Progress Report 2004-2006' (DKCRC Working Paper No 31, Desert Knowledge CRC, Alice Springs, 2009).

2 K Akerman and J Stanton, Riji and Jakoli: Kimberley Pearlshell in Aboriginal Australia Monograph Series 4 (Northern Territory Museum of Arts and Sciences, 1994).

3 G Miers, 'Cultivation and Sustainable Wild Harvest of Bushfoods by Aboriginal Communities in Central Australia' (Research Report, Rural Industries Research \& Development Corporation, Canberra, 2004).

4 P Everard et al, Punu: Yankunytjatjara Plant Use (2nd ed, IAD Press, 2002).

5 See Ryder et al, above $\mathrm{n} 1$.

6 J Cleary, 'Business Exchanges in the Australian Desert: It's About More than the Money' (2012) 7(1) Journal of Rural and Community Development 1.

7 Ibid.

8 J Cleary et al, 'Hands Across the Desert: Linking Desert Aboriginal Australians to Each Other and to the Bush Foods Industry' (Research Report, Desert Knowledge Cooperative Research Centre, Alice Springs, 2009). 9 Ibid.
} 
Changing this situation of Aboriginal peoples' peripheral inclusion in the industry is one means of increasing broader Aboriginal participation in the Australian economy. Increased economic participation has been promoted as a means of decreasing disadvantage of Aboriginal peoples in Australia, ${ }^{10}$ and there is thus considerable interest and activity directed at 'improving' the current situation. Attempts have been made in central Australia to increase the participation of remote Aboriginal peoples in the bush-foods industry through a variety of mechanisms, and with mixed results. ${ }^{11}$ Most of these have been based on Western understandings of trade and commerce. To date, there has been little research undertaken on understanding the current ways in which Aboriginal peoples are already participating in the bush-foods industry, particularly those engaged in bush harvesting. ${ }^{12}$

The Desert Knowledge Cooperative Research Centre, ${ }^{13}$ through its 'Bush Products from Desert Australia Core Research Project' situated within a programme of research entitled 'Thriving Desert Economies', ${ }^{14}$ invested considerable resources in understanding and attempting to improve current participation rates by Aboriginal peoples. In part, this project helped researchers to understand the complex socio-cultural differences that exist between the Aboriginal harvesters and the rest of the bush-food supply chain in which they are situated. These differences relate to the 'two worlds' in which the women walk: the world of Western commerce, and their own cultural imperatives related to the harvesting of bush foods.

A critical factor in the 'two worlds' paradigm is the importance of the social and cultural context and dual knowledge systems within which industry participants are situated and operate. ${ }^{15}$ For example, Aboriginal harvesters of fruit and seeds in the Northern Territory have articulated a range of reasons for harvesting: it is a customary activity associated with health and wellbeing; it helps to pass on traditional knowledge; and it is part of caring for Country - a cultural responsibility. ${ }^{16}$ Since harvesting activities constitute only a small part of the individuals' income, all of these reasons are in addition to, and arguably

10 Families, Housing, Community Services and Indigenous Affairs, Closing the Gap on Indigenous Disadvantage: The Challenge for Australia (AGPS, 2009).

11 J Gorman et al, 'Assisting Australian Indigenous Resource Management and Sustainable Utilization of Species Through the Use of GIS and Environmental Modelling Techniques' (2008) 86 Journal of Environmental Management 104.

12 Ryder et al, above $\mathrm{n} 1$.

13 The Desert Knowledge Cooperative Research Centre (DKCRC) was formed under the Australian Government Cooperative Research Centre Programme managed by the then Department of Innovation, Industry, Science and Research. DKCRC operated between July 2003 and June 2010.

14 DKCRC, Legacy Website <http://www.desertknowledgecrc.com.au>

15 Cleary, above $\mathrm{n} 6$.

16 F Walsh and J Douglas (Alyawarr Speakers from Ampilatwatja), 'Angka Akatyerrakert: A Desert Raisin Report' (DKCRC, Alice Springs Australia 2009) < http://www.desertknowledgecrc.com.au/researchimpact/ downloads/DKCRC_Angk-Akatyerr-akert_A-Desert-raisin-report.pdf $>$ 
override, the motive of financial return. ${ }^{17}$ For these participants, harvesting is undertaken in the context of a world view which prioritises the importance of cultural traditions associated with kinship relationships and customary governance systems over economic participation. For non-Aboriginal and nonremote participants whose primary incomes are derived from the industry, participation is fundamentally for economic reasons and supported by a Westernised world view of what that means - a world in which negotiated relationships, rather than kinship relationships, are the norm. Understanding these differing perspectives is important, particularly at the nexus in bush-food supply chains where intercultural trade occurs. These perspectives impact upon the value attached to resource flows, financial return, relationships between chain participants, and, indeed, in considerations of the 'products' themselves as both cultural icons and commodities.

This chapter discusses a participatory action research (PAR) project undertaken with remote Aboriginal harvesters of katyerr ${ }^{18}$ (Solanum centrale, bush tomato or desert raisin), entitled 'Information = Power: Walking the Bush Tomato Value Chain' (hereafter I = P project). ${ }^{19}$ The chapter focuses on the participatory nature of the project and discusses the effectiveness of PAR as a methodological approach for negotiating the 'two worlds' paradigm. Further, it signals the importance of PAR as a methodological approach that can assist in navigating the complexities associated with intellectual property (IP) rights: for example, in understanding Aboriginal peoples' customary use rights around knowledge of bush plants and Western imperatives around efficiently defined IP rights. Developing governance systems for the commercial use of biological resources where there may be competing and/or complementary cultural and commercial imperatives around such resources is an urgent priority.

The chapter first grounds PAR in contemporary literature; provides background information on the I = P project; describes the activities undertaken within the project; and discusses the lessons from these in the context of the PAR literature. Following this, I reflect on my own learning as a participant in the project. Finally, the chapter provides recommendations on using PAR as a research approach in further bush-foods and bush-medicine research. This has relevance in the protection of Aboriginal ecological knowledge (AEK) in the context of the increasing commercialisation of native species. The chapter

\footnotetext{
17 Ryder et al, above $\mathrm{n} 1$.

18 A number of different Aboriginal names in the central Australian desert region are also used for Solanum centrale, the fruit known commercially as 'bush tomato'. These include akatyerr, katyerr, akatyerre, katyerre, kampurarrpa, kampurarpa and jungkunypa. 'Bush tomato' is also known in non-commercial contexts as 'desert raisin.' The term 'katyerr' will be used here, except where otherwise explained, as a mark of cultural respect and as acknowledgement that it was the term consistently used by the Aboriginal participants during the course of the project being reported on in this chapter.

19 DKCRC, 'Information = Power: Walking the Bush Tomato Value Chain' (Project Proposal to NT NRM Board, Alice Springs, 2008).
} 
highlights one example (plant breeder's rights) of some of the issues and challenges that could be associated with using this mechanism as a tool to protect AEK and IP rights.

\section{Participatory Action Research}

PAR is an approach to enquiry that attempts to incorporate the elements of both participation and action implied in the name. It is a process aimed at identifying a problematic social situation or existing phenomenon, understanding it, and then taking some action to rectify the problem, or changing the situation, with the active participation and intervention of the social actors who are the 'subjects' of the research. It attempts to integrate experience, action and reflection. ${ }^{20}$ Reason describes two primary objectives in PAR: to produce both knowledge and action that is directly useful; and consciousness-raising (learning) that creates empowerment.

PAR as a research approach has its roots in research on social change in developing countries (particularly on colonised and oppressed peoples). ${ }^{21}$ In the 1970s there emerged a growing and radical critique of social theory amongst those within the social science community (most particularly within the fields of sociology, anthropology, education and theology) engaged in research in the developing world. This critique related to academic insistence on value neutrality and its associated objectivity, plus academic rigour in the pursuit of science knowledge, when, simultaneously, social researchers were confronting situations of massive structural crises, oppression and social change related to increasing capitalism and modernisation in the developing countries with which they were engaged. ${ }^{22}$ There resulted a move away from academic aloofness towards researchers taking personal positions that enabled them to take a new view of knowledge. Techniques were developed that allowed researchers to apply knowledge in social and political situations to effect transformation, and this led to the development of participatory methods of social inquiry. ${ }^{23}$ Primary aims were to make knowledge more accessible to research 'subjects' and to help them to understand that knowledge could

\footnotetext{
20 P Reason, 'Human Inquiry as Discipline and Practice' in P Reason (ed), Participation in Human Inquiry (Sage Publications, 1994) 40.

21 P Freire, Pedagogy of the Oppressed (Herder \& Herder, 1970); O Fals-Borda, 'Participatory (Action) Research in Social Theory: Origins and Challenges' in P Reason and H Bradbury (eds), Handbook of Action Research (Sage Publicatons, 2001) 27.

22 Fals-Borda, ibid.

23 Ibid.
} 
be used as an instrument of power and control. ${ }^{24}$ In recent times, PAR has been increasingly used in a number of fields of enquiry, including health, education, organisational change management and agriculture. ${ }^{25}$

PAR views social reality not as something pre-given or pre-defined but as something co-created. ${ }^{26}$ Epistemologically speaking, PAR implies a methodological approach at the macro or 'stage-setting' level, ${ }^{27}$ and that favours collaborative forms of enquiry as the means for gaining knowledge and applying it. ${ }^{28}$ It is at once constructivist, dialogical and proactive, attempting to centralise participant and researcher values, ${ }^{29}$ and falls most easily within the critical theory paradigm. ${ }^{30}$ PAR can therefore be seen as a useful methodological approach to research questions of which differing knowledge systems and associated world views (for example, Western science and traditional ecological knowledge) are a feature, because it emphasises central participation in the research by people who are knowledgeable about the research topic from multiple perspectives, affected by it, and may wish to use the research to effect change.

There are numerous recent examples of PAR use in co-research between indigenous and non-indigenous peoples, both in Australia and internationally, ${ }^{31}$ and it is an increasingly favoured approach with indigenous peoples in health research in particular. ${ }^{32}$

\footnotetext{
24 Freire, above n 21.

25 W F Whyte, Participatory Action Research (Sage Publications, 1991).

$26 \mathrm{~K}$ Breu and C Hemingway, 'Researcher-Practitioner Partnering in Industry-Funded Participatory Action Research' (2005) 18(5) Systemic Practice and Action Research 437.

27 S Kidd and M Kral, 'Practicing Participatory Action Research' (2005) 52(2) Journal of Counseling Psychology 187.

28 P Reason, 'Sitting Between Appreciation and Disappointment: A Critique of the Special Edition of Human Relations on Action Research' (1993) 46(10) Human Relations 1253.

29 Kidd and Kral, above $\mathrm{n} 27$.

30 Following J G Ponterotto, 'Qualitative Research in Counseling Psychology: A Primer on Research Paradigms and Philosophy of Science' (2005) 52(2) Journal of Counseling Psychology 126.

31 See, for example, E Tuck, 'Re-visioning Action: Participatory Action Research and Indigenous Theories of Change' (2009) 41 Urban Review 47; J Taylor et al, 'The Station Community Mental Health Centre Inc: Nurturing and Empowering' (2010) 10 Rural and Remote Health 1411; C de Crespigney et al, 'A Nursing Partnership for Better Outcomes in Aboriginal Mental Health, Including Substance Use' (2006) 22(2) Contemporary Nurse 275; J McIntyre, 'Yeperenye Dreaming in Conceptual, Geographical and Cyberspace: A Participatory Action Research Approach to Address Local Governance Within an Australian Indigenous Housing Association (2003) 16(5) Systemic Practice and Action Research 309; G A Getty, 'The Journey Between Western and Indigenous Research Paradigms' (2010) 2(1) Journal of Transcultural Nursing 5; G V Mohatt et al,'Unheard Alaska: Culturally Anchored Participatory Action Research on Sobriety with Alaska Natives' (2004) 33(3-4) American Journal of Community Psychology 263; N B Wallerstein and B Duran, 'Using Community-based Participatory Research to Address Health Disparities' (2006) 7 Health Promotion Practice 312; and K Tsey et al, 'Indigenous Men Taking Their Rightful Place in Society? A Preliminary Analysis of a Participatory Action Research Process with Yarrabah Men's Health Group' (2002) 10(6) Australian Journal of Rural Health 278.

32 F Baum et al, 'Continuing Professional Education, Glossary: Participatory Action Research' (2006) 60 Journal of Epidemiological Community Health 854.
} 
An important component of PAR is the positioning of the researchers as colearners and facilitators, rather than as objective observers. ${ }^{33}$ The emphasis is on collaboration and participation, rather than the detached perspective of objectivity associated with positivistic approaches. Carr and Kemmis describe three different aspects of the role of the researcher in PAR approachestechnical, practical or emancipatory - and that which is adopted is dependent on the nature and purpose of the research activity being undertaken. ${ }^{34}$

Under this schema, PAR differs significantly from other research approaches in that it is not extractive: that is, researchers are not 'experts' who study their subjects and then go away to write their papers. Rather they are co-participants, experiencing a problem situation or phenomenon in order to better understand it and to assist in changing it. ${ }^{35}$ Participatory approaches have as an ideal the democratically negotiated processes between academics and other participants in the research. ${ }^{36}$ One criticism of PAR relates to the balance of power in PAR and a legacy of colonialism in academic-indigenous research partnerships. ${ }^{37}$ This colonial legacy (following Smith) privileges some knowledge types and the world view from within which such knowledge is formed, based on externally driven research and interventions. Power, and the challenge this presents to the democratic ideal of equal participation, is related to the level of influence different participants are able to wield in the research. ${ }^{38}$ It is important to consider, therefore, the influence of externalities to the research, such as language (including whose language is used to discuss and formulate the research), research funding imperatives and the extent to which the proposed research sits within a broader institutional research framework or context.

\section{Context to the I = P Project}

$\mathrm{I}=\mathrm{P}$ arose out of a Desert Knowledge Cooperative Research Centre (DKCRC) stakeholder consultation workshop held in Alice Springs in April 2007. ${ }^{39}$ A number of bush-foods industry participants, both Aboriginal and nonAboriginal, attended, including harvesters, growers, wholesalers, processors and retailers. The stated aim of the workshop was to seek guidance from

33 P Reason and H Bradbury, 'Inquiry and Participation in Search of a World Worthy of Human Aspiration' in P Reason and H Bradbury (eds), Handbook of Action Research (Sage Publications, 2001) 1.

34 W Carr and S Kemmis, Becoming Critical: Knowing Through Action Research (Deakin University Press, 1983).

35 Baum et al, above $\mathrm{n} 32$.

36 L W Green et al, Study of Participatory Research in Health Promotion: Review and Recommendations for the Development of Participatory Research in Health Promotion in Canada (University of British Columbia: Royal Society of Canada, 1995).

37 L T Smith, Decolonizing Methodologies: Research and Indigenous Peoples (Zed Books, 1999).

38 M Cargo et al,'Can the Democratic Ideal of Participatory Research Be Achieved? An Inside Look at an Academic-Indigenous Community Partnership' (2008) 23(5) Health Education Research 904.

39 DKCRC, above n 19. 
participants about the direction of proposed research to be undertaken by DKCRC in its 'Bush Products from Desert Australia' core project. ${ }^{40}$ Workshop participants endorsed the adoption of a value-chain approach, ${ }^{41}$ but also determined that the research should be participatory, and focus primarily on katyerr as a high-demand desert product in the bush-foods industry. Katyerr is also highly significant for its spiritual importance, featuring in the Dreaming stories of many desert Aboriginal peoples. ${ }^{42}$

Participants believed that understanding the social context of the supply/value chain must precede any operational changes. ${ }^{43}$

The participants outlined a number of different personal values related to bush food during the course of the workshop. These values 'related to the importance of bush foods as an industry and an integral part of Indigenous livelihoods'.$^{44}$ Participants articulated values related to community and land and the recognition of cultural values: for example,

future for kids; good healthy food; health food [for] colds; keep it strong for the young people; it's where we come from; land management; we need to live with the land; management of the land; integrity of the food related to Aboriginal values and the land; recognition of where it comes from. ${ }^{45}$

Other value statements related to the growth and development of the bushfoods industry and benefits for individuals, and included:

It's my livelihood; exciting new and growing industry; economic

- work hard; it's a catalyst for creating economies; self-sufficiency; independence; ownership. ${ }^{46}$

Participants clearly expressed values that demonstrated the importance of bush food both commercially and culturally. This can be summed up in the statement:

\footnotetext{
40 Ibid.

41 The value chain concept was first described by Michael Porter, see M Porter Competitive Advantage (The Free Press. New York, 1985) 11 and encompasses a chain of activities undertaken within firms or more broadly at the industry level where each activity in the chain adds value to a product as it moves from supplier to the market. Value chain analysis has become an accepted, useful, contemporary tool for determining where competitive advantage can be generated for the actors within value chains, particularly in the agriindustry sector, see K Bryceson and C Smith, 'Abstraction and Modelling of Agri-food Chains as Complex Decision Making Systems' (Proceedings of the EAAE Conference on 'System Dynamics and Innovation in Food Networks' Innsbruck-Igls, Austria, February 18-22, 2008). The bush-food industry can be classified as part of this sector.

42 P Latz, Bushfires and Bushtucker: Aboriginal Plant Use in Central Australia (IAD Press, 2005).

43 Hassall and Associates Pty Ltd, 'Value Chain Workshop Notes for Desert Knowledge CRC' (Report no.

AU1-517, DKCRC, Alice Springs, May 2007).

44 Ibid, 3

45 Ibid.

46 Ibid.
} 
... [the] challenge lies in recognising that bush foods cross two cultures (economic and Indigenous) and needs [sic] to deliver values to both. ${ }^{47}$

Among the workshop participants was a group of remote Aboriginal women from a settlement approximately 270 kilometres north-east of Alice Springs, in the Northern Territory, who were invited to attend because of their involvement in the bush-foods industry as bush harvesters. These women made a number of comments ${ }^{48}$ related to better understanding the movement of the katyerr they picked on their land after the fruit left their community. One woman said, 'It would be good to know where our food goes.' This statement was pivotal to both the rationale for the subsequent development of $\mathrm{I}=\mathrm{P}$, and in formulating the activities undertaken within the project. As will be seen in the discussion section of this chapter, it was also pivotal in terms of the 'two worlds' paradigm of bush foods, and the various understandings and positions brought to the project by its participants.

Following the workshop, the DKCRC successfully sought funding from the Northern Territory Natural Resources Management Board to undertake the I = $\mathrm{P}$ project, which articulated its broadest aim as enabling the bush harvesters to 'see where their food goes'.

Along with the initial group from the stakeholder meeting, one other woman expressed her interest in being part of the $\mathrm{I}=\mathrm{P}$ project. She was not involved in bush harvesting but, together with her partner, operated a small commercial katyerr plantation where fruit was harvested by hand. The project participants also included two representatives from a reference group ${ }^{49}$ established to guide bush-harvest research in the broader Bush Products Core Project. In all, there were twelve project participants, including me and other research and supporting team members. The group determined that a physical journey, following katyerr to various (commercial) destinations beyond central Australia, would be a useful way of understanding where the fruit went, how it was used and who used it.

\section{The Project}

Ethical considerations were paramount in conducting this project. Researchers were mindful of the need to ensure it was conducted within Western regulatory

\footnotetext{
47 Ibid.

48 Comments were made through an interpreter, because English is not a primary language for this group of women.

49 Merne Altyerr-ipenhe (Food from the Creation time) Reference Group was established to guide bushharvest research activities. It comprised respected Aboriginal women recognised as cultural custodians of bush-harvest knowledge, some of whom were also bush-food industry participants.
} 
frameworks for human research, and also to ensure the project met Aboriginal participants' needs and expectations in this regard. While Western frameworks are aimed at protecting research participants, including Aboriginal peoples, the DKCRC also produced a set of specific research protocols ${ }^{50}$ developed by remote Aboriginal desert peoples and used consistently across the life of the CRC. The project was conducted in accordance with these protocols, and also obtained ethics approval from the Central Australian Human Research Ethics Committee (CAHREC) ${ }^{51}$ CAHREC is a committee of the Northern Territories Department of Health, and considers both health and non-health research involving Aboriginal peoples in the Northern Territory. It does this through its Aboriginal Committee, whose primary aim is to protect Aboriginal peoples in the Northern Territory in the conduct of research, and to ensure Aboriginal peoples benefit from such research. ${ }^{52}$ The committee, which aims to span all major language groups in the Northern Territory, includes at least one male elder and one female elder among its all-Aboriginal members, as well as at least one person with research experience in non-health related research.

Following approval, the project team met at a workshop in Alice Springs in July 2008, during which the bush harvesters discussed the project and outlined what they currently knew about what happened to the katyerr they picked for sale. This session incorporated both talking and drawing, enabling participants (some of whom have English as a second or third language) to express their knowledge both verbally and pictorially. It provided the baseline observations of these participants about their knowledge prior to undertaking the journey. I noted that each of the women's drawings included clearly marked direction indicators, establishing where they were currently in relation to their home community. The activity also enabled the research team to fully explain their position as researchers and facilitators, and to talk about what they might do after the project: for example, writing about the project, and making a DVD and picture story boards so that other Aboriginal women engaged in harvesting activities might learn more about the market aspects of katyerr. In accordance with DKCRC research protocols, media release forms giving permission to film and take photographs of project activities were explained and completed by participants. Researchers undertook to ensure that any such materials would be available for review by all participants before being released more generally, and this was done at the completion of the project.

\footnotetext{
50 DKCRC, Aboriginal Research Engagement Protocol Template (DKCRC, Alice Springs, 2006).

51 Central Australian Human Research Ethics Committee, 'Walk the Value Chain: Information Equals Power' (Ethics approval letter, 14 July 2008).

52 Northern Territory Government, Central Australian Human Research Ethics Committee, Policy and Procedures Manual <http://www.health.nt.gov.au/library/scripts/objectifyMedia.aspx?file=pdf/12/26. pdf\&siteID $=1 \&$ str_title $=$ CA HREC Policies and Procedures.pdf $>$
} 
Immediately following the workshop, we travelled to the Sunshine Coast (via Brisbane) in Queensland. On arrival at the airport in Brisbane, the harvesters asked where they were in relation to their home communities, and spent some time establishing the direction in which those communities lay and the distance they had travelled. This was the first major journey many of the harvesters had made by air, and it seemed important for them to establish exactly where they were in relation to where they had come from.

We then travelled by road to the Sunshine Coast, where we met with an Aboriginal woman who operates a restaurant and catering business. We were officially 'welcomed to Country', as is customary between Australian Aboriginal peoples visiting locations beyond those with which they have immediate cultural ties. This business operator specialises in the use of bush foods, and participants experienced a commercially prepared bush-foods meal, the main course of which featured katyerr. For many of the harvesters, this was a new experience of bush food, prepared in quite a different way from the traditionally prepared bush food they were familiar with. Following the meal, the harvesters were able to share with the entire group their stories of bush food, using a series of photographs and story boards which had been prepared by members of the project team during earlier research with the bush harvesters. The harvesters appeared particularly animated and excited during this part of the visit, and were very keen to talk about who they were, where they came from and how they harvested bush food. In reviewing the subsequent video footage, I also noted that there was considerable discussion among the harvesters in their own language. They also pointed out the children and grandchildren in the story boards and talked about how important it was to 'keep the knowledge strong' with these young people. The harvesters also made a point of asking about the origin of the katyerr prepared in the meal they had eaten. The business operator explained that she bought it from her supplier, but that she wasn't sure from which part of central Australia it had started its journey.

After an overnight stay in Maroochydore, the group flew to Melbourne, Victoria. Again, on arrival the harvesters spent time establishing where they were in relation to their home communities. In Melbourne, the group visited a number of non-Aboriginal owned and operated commercial entities associated with bush food. These included a processing factory, a distribution business and a large supermarket.

At the processing factory, we were shown through the processes associated with preparing, cooking, bottling, labelling and packaging various bush foods for sale and distribution. The women were interested in learning about these various processes, but one incident in the factory stood out in my review of the video footage. When the harvesters viewed large bags of raw product that had been received at the factory from various suppliers around Australia, they 
were highly animated and keen to know from where the bags had originated. Comments included, 'Maybe this [wattleseed, Acacia spp.] came from [community name] near us? Those ladies have been picking lots of this.' There was also much interest in unfamiliar (non-desert) products, and the women wanted to know who picked it, where it grew and how it got to the factory.

The group met with members of a distribution company which managed the movement of finished products from the factory to retail outlets. The company presented information about the importance of continuity of supply as a requirement for maintaining shelf-space of finished products at supermarkets. My review of the video footage indicated that there appeared to be lower levels of interest in this part of the activity. I noted that the presentation of information was quite abstract, and did not include any specific place-based references.

At a large supermarket, the group saw the finished products on the shelves. The harvesters expressed high interest in the variety of products available and, again, interest in where it had originated.

The group attended an up-market restaurant in the heart of Melbourne that features bush food as an integral part of its menu. This restaurant is owned and operated by an Aboriginal woman who described herself as the traditional owner of land in the Melbourne region. She welcomed us to her Country and provided some history and context about her family and about her business, and served a multi-course meal that featured bush foods. I noted (with some amusement) the various visual expressions of some of the harvesters as they tasted some items on the menu. Some of the dishes were clearly appealing, but some were perhaps removed from the women's expectations of what they would (or should) taste like.

The final activity undertaken by the harvesters was to redraw their understandings of 'where their food goes', based on the journey they had made. Again I noted the clearly marked direction indicators on the maps drawn by participants. The maps were not drawn in the usual abstract manner common in geography textbooks - that is, with 'north' at the top of the page, 'south' at the bottom, and 'west' and 'east' to the left and right respectively. Instead, the maps were drawn in relation to the direction the drawer was oriented. For example, one participant was facing south, and so drew her map with 'south' at the top of the map and 'north' at the bottom. 


\section{Project Outcomes}

In all, the physical journey occupied one week. It provided many opportunities for learning, both on the part of the harvesters and for me. The harvesters were able to articulate a greater understanding of 'where their food goes', and this was evidenced in discussions and, particularly, in pictorial representations completed at the conclusion of the project. There is also evidence that, as a result of undertaking the journey and forming new relationships with others in the supply chain, the harvesters have subsequently made some changes in the way in which they sell their fruit. In some cases, they are selling more directly into the chain, and are initiating these transactions themselves, rather than relying on traders making buying trips to their communities. It is likewise evident that they have increased their returns via these transactions, and are receiving higher payments than previously.

\section{Discussion}

In an earlier section of this chapter, I highlighted a comment made by a participant in an early stakeholder workshop: 'It would be good to know where our food goes.' In this section I want to reconsider that statement and the multiple meanings that have emerged in light of deeper understandings developed as a result of participating in the $\mathrm{I}=$ P Project.

From a Western perspective of participation in the bush-foods industry, there is a tendency to see the current participation of remote Aboriginal peoples as marginal, in that financial returns to this group are not high. The assumption is that increasing participation and knowledge of the Westernised view of commerce and what it entails, and the imperative to decrease costs and increase profit, is universally desirable. Using a supply or value-chain framework to examine participation and to work towards increasing economic participation is a logical extension of this thinking. In the context of the I = P project, both my interpretation and understanding of the comment 'It would be good to know where our food goes' and the broader goals of the DKCRC 'Bush Products from Desert Australia' core project were framed by this thinking. From that position, the I = P project, and my role as co-researcher, could be seen to encompass the 'technical' aspects of participatory action research outlined by Carr and Kemmis. ${ }^{53}$ Indeed, this is how I saw my role - as a facilitator in promoting learning that would increase the 'technical' capacity of the harvesters to participate in the bush-foods industry. I interpreted the harvesters' comment to mean that if they knew where 'their' food went, what happened to it (in relation to how others

53 Carr and Kemmis, above n 34. 
value-added to it), who profited and why, they would then come to see that there could be opportunities for them to play a greater role in the value-adding process. Importantly, I also assumed that this was a shared interpretation. I also understood that increasing the harvesters' capacity to develop more direct relationships with others in the supply chain could help them secure buyers for their fruit, thus increasing competition and returns. Research in agrifood industries has shown that better connecting component parts of supply chains can improve efficiencies and increase multi-directional information flow, and to some extent this has occurred in this case. In the context of this chapter, however, my intent is to focus on the value of the participatory process as a learning mechanism, and in particular to highlight its value (in my case) for better understanding the 'two worlds' paradigm referred to in the introduction.

As a participant in the $\mathrm{I}=\mathrm{P}$ project, and through the subsequent building of deeper relationships with the Aboriginal harvesters, I have come to develop different perceptions and understandings of bush food beyond the context of participation in an industry. These perceptions and understandings are increasingly shaping my thinking and research. To highlight the impact of these relationships in changing my perceptions, I will describe an incident that occurred subsequent to the I = P journey.

In another component of the 'Bush Products from Desert Australia' core project, horticultural development of 'bush tomatoes' ${ }^{54}$ has been pursued. As part of that work, a trial planting of plants from various desert locations was developed. Plants were germinated from held seed stock. The aim of this research was to increase knowledge of the horticultural production requirements of 'bush tomatoes' as a means of developing a supply mechanism that was more reliable than bush harvest, with its inherent issues of climate variability that could sometimes limit supply. It would also provide information about horticultural production to enable the successful development of Aboriginal horticulturally based bush-food enterprises.

Very early in the development of this horticultural trial (and prior to the $\mathrm{I}=\mathrm{P}$ project), bush harvesters were invited to visit the trial site to ensure that there was Aboriginal involvement and consultation around the project. There was no immediate indication from the bush harvesters that they had any issues with it, and they were politely attentive to the information that was shared with them. However, after developing greater mutual trust and much deeper relationships with the harvesters, I later learned that they were quite horrified by this project. At the time of their visit (which was during the growing season of katyerr), there had been very little bush harvest of katyerr in central Australia because of

54 The term 'bush tomatoes' is used here because in the context of the broader DKCRC project, this was the term consistently used, and is related to the commercial use of the fruit. 
prevailing dry conditions that were not conducive to its growth in that season. The harvesters' interpretation of what they saw at the trial site (numerous rows of healthy katyerr plants) was later explained to me as a question: 'Why did you mob go out bush and dig up all the katyerr plants and put them in that place in Alice Springs? There was none left in the bush for us to pick.' It had not occurred to me until that time that the harvesters could interpret what we were doing at the trial site in this way: that is, for them it explained why there was there was no bush katyerr for the women to harvest from the wild.

This anecdote highlights two important points. First, the thinking that underpins the assumptions we make is firmly rooted in the world view within which the thinking occurs, and the thinking itself is framed within the language in which the thoughts are formed. Secondly, it is only through the development of trust found in deeper relationships and engagement with others possessing different world views that one can approach new understandings based on those different world views. Taking a participatory approach to this project has, in that sense, provided the macro environment and indeed 'set the stage' for learning and its application to occur in the manner raised by Kidd and Kral. ${ }^{55}$

In applying this new understanding, how did I reinterpret the statement 'It would be good to know where our food goes'? Did it mean something different from what I initially understood it to mean, and was the question itself framed from within a language that recognised different emphases and signifiers of what was important - different understandings of spatial and temporal concepts, for example? If one considers the actions of the harvesters at various stages along the physical journey — the desire to 'place' themselves in relation to their home communities on arrival in different locations, asking questions about where raw product inputs had originated and who had harvested them, the way in which directions were depicted on their pictorial representations of their journey, their animation in talking about their own harvesting activities, and the importance of passing on knowledge to their children and grandchildren one can see a pattern emerging. This pattern, I would argue, relates primarily to the importance the harvesters attach to 'place' and 'belonging' both for themselves and the bush food they harvest. This importance relates to both the people themselves and the foods they harvest in the context of interrelationships between land and people. So, the statement 'It would be good to know where our food goes' may be intrinsically and inextricably linked to place-based cultural identity, to language, and to customary systems of governance related to land, people and law. This may translate to a sense of 'belonging with' rather than 'ownership of' the fruit they harvested. 
Indeed, this relatedness is highlighted by Walsh and Douglas in their research on sustainable bush harvest, reported in Ryder et al. ${ }^{56}$ In this research, remote Aboriginal harvesters articulated the cultural importance of some bush-food species with commercial value, including katyerr. Walsh and Douglas argued that katyerr and other bush-food plants continue to be 'key characters in Jukurrpa (dreaming) and ceremony' ${ }^{57}$ They also reported that certain Aboriginal peoples consider themselves to be custodians of these resources. This has important implications in developing governance systems that protect AEK, because it clearly implies an existing governance system for the control and use of these resources which predates any Western legal framework. It is also interesting to note the use of the term 'custodian' rather than 'owner' in relation to the plants. Again, this suggests belonging 'with', rather than belonging 'to', in the context of relationships between land, people and law.

On the question of language and its role in shaping thought, an important study by Lera Boroditsky and Alice Gaby was conducted with Pormpuraawanlanguage speakers in Pormpuraaw, a remote Aboriginal community on Cape York. ${ }^{58}$ In this study, Boroditsky and Gaby demonstrated the differences between the way Pormpuraawan speakers and English speakers represented time spatially. They concluded that cross-cultural difference in thought is about more than style or preference, and is instead intrinsically related to the language used to shape the thoughts expressed. While this study was conducted on Cape York, Boroditsky and Gaby also pointed to similar differences in central desert Aboriginal-language speakers.

The extractive market process associated with bush food in central Australia has developed only in the past thirty to forty years, ${ }^{59}$ but there is evidence that Aboriginal peoples have engaged in customary trade through kinship networks and as part of subsistence economies for at least 5,000 years. ${ }^{60}$ It is highly likely that innovative practices associated with sustainable harvesting, such as the selection, manipulation and management of biological resources, would have arisen as a result. ${ }^{61}$ In that sense, Western ideas of 'value adding' and the notion that this occurs post-extraction and only after the raw product has been sold by Aboriginal peoples to others in the value chain, may be incorrect. Cleary et al report, for example, on a customary post-harvest treatment of katyerr where the fruit is rubbed with clean sand to remove minute hairs reported by the harvesters to cause stomach irritation. ${ }^{62}$ An important point here is that the AEK

56 Ryder et al, above $\mathrm{n} 1$.

57 Walsh and Douglas, above n 16.

58 L Boroditsky and A Gaby, 'Remembrances of Times East: Absolute Representations of Time in an Australian Aboriginal Community' (2010) 21(11) Psychological Science 1635.

59 Miers, above n 3.

60 Akerman and Stanton, above n 2.

61 Walsh and Douglas, above n 16.

62 Cleary et al, above n 8 . 
that is being applied in selecting, manipulating and managing 'wild' species, and in applying any customary treatments to harvested fruit, is not currently recognised in the contemporary commercial trade of bush-harvested fruit, nor reflected in the prices paid for raw product. ${ }^{63}$ I raise these issues here simply to highlight the value of PAR in developing 'two world' understandings, and its usefulness in revealing the many layers that might need to be peeled back to fully understand the intercultural complexity associated with both customary and commercial paradigms related to bush foods and their uses.

As a researcher, comprehension of the 'two worlds' paradigm (and thus the capacity to begin to consider complex questions outside my own world view) would not have been possible without first developing the relationships that have formed in sharing the $\mathrm{I}=\mathrm{P}$ project experience. For that reason, it has been an enabling and perhaps emancipatory process, ${ }^{64}$ which has allowed the formation of a new perspective outside the personal and institutional constraints within which my original thinking was formed. The notion of experience, action and reflection $^{65}$ inherent in PAR has been applied to my own approaches to better understanding bush foods and the various lenses through which the resources and activities associated with them might be viewed.

\section{Conclusion}

The purpose of this chapter has been to describe and discuss the effectiveness of PAR as an approach to research in the bush-foods area through the case-study exploration of the I = P project and its learning outcomes. The case study has provided useful insights into new ways of considering research approaches that emphasise participation, learning and application. I now conclude by drawing inferences from those insights and applying them to consideration of research issues related to the protection of AEK.

The protection of AEK is an urgent and high-priority area. Aboriginal peoples' legal control over this knowledge must be clear and unambiguous, and an appropriate regulatory system is an essential step in achieving that control. However, it is equally essential that such work is firmly grounded and tested within specific, 'real world' contexts where development around native biological resources is already occurring.

Participatory approaches which value and respect (and privilege equitably) AEK, customary law and Western legal systems will be essential in creating

63 Cleary, above n 6.

64 Carr and Kemmis, above $\mathrm{n} 34$.

65 Reason, above n 20. 
both a new regulatory administrative system and an environment in which it can flourish. The place where AEK, Aboriginal customary law and Western legal systems come together will undoubtedly require intercultural negotiation and translation to develop a new regulatory framework. The primary objectives of PAR as outlined by Reason ${ }^{66}$ — that is, to produce both knowledge and action that is directly useful, and consciousness raising (learning) that creates empowerment - would seem a useful place from which to begin the process.

A specific and timely example of how PAR might be used in this context is in how AEK needs to be considered in any development of plant breeders' rights (PBRs) on bush-food and bush-medicine plants. The Plant Breeder's Rights Act 1994 (Cth) ${ }^{67}$ provides the mechanism for granting proprietory rights to breeders of certain new plant varieties and fungi in Australia. Currently, there is no existing legal requirement to recognise Aboriginal ownership of plant materials, nor any consideration of AEK in the development of varieties registered under the Plant Breeder's Rights Act. It is important to acknowledge that there are some concerns about the validity of some plant breeder's rights (PBRs) registrations under the Act, and a level of complexity exists with regard to the application of the Act. ${ }^{68} \mathrm{My}$ intent in this section is not to advocate or otherwise for the application of PBRs in relation to bush foods and bush medicine. However, work on developing PBRs for native species has already begun in Australia, so it is relevant to consider it in relation to AEK issues.

In the bush-foods context, the primary aim of PBRs is to develop and register new plant varieties which have desirable characteristics that decrease production costs and increase returns: for example, plants that have a higher fruit yield and that are adaptable to a range of growing and mechanical-harvesting conditions. For those bush-foods species that enter the market predominantly through harvest from the wild (like 'bush tomatoes'), PBRs are seen as a means of increasing and stabilising supply through horticultural production of 'improved' varieties.

There are multiple AEK protection issues to consider. These include but are probably not limited to:

- Who has cultural ties to the plants being considered for 'improvement'? Who are the plant's custodians? How will they be involved? 'Bush tomato', for example, is an extremely wide-ranging plant that grows across large areas of Western Australia, South Australia and the Northern Territory. ${ }^{69}$ Many Aboriginal peoples will have cultural ties to the particular plants that

\footnotetext{
66 Reason, above $\mathrm{n} 20$.

67 Plant Breeder's Rights Act 1994 (Aus.).

68 J Sanderson, 'Intellectual Property and Plants: Constitutive, Contingent and Complex', in K Bowrey, M Handler and D Nicol (eds), Emerging Challenges in Intellectual Property (Oxford University Press, 2011). 69 Purdie et al 'Solanaceae' in Flora of Australia Vol. 29 (Austalian Governement Printing Service, Canberra, 1982).
} 
grow in their Country. These cultural ties include the Dreaming stories and AEK associated with those plants. What will be the cultural ramifications of creating 'improved' plants from hybridisations of plants from different Countries? What will the Stories for these 'improved' plants be, and who will be able to speak them, paint them and pass them on to children and grandchildren? Where will these 'improved' plants fit in the place-based relationships between people, land and customary law? Where will they belong?

- Will the new plants have a Dreaming? Or will they be like the cane toads that are infesting the ancestral lands of the Yanyuwa people in the Northern Territory and that have no 'law' ? $^{70}$

- Is the word 'improved' a culturally acceptable term, in that it implies that the plants themselves require something done to them to make them better?

- How will benefit-sharing arrangements and business models to commercialise such hybridisations be developed? Who will benefit financially, and who will decide on those who need to be consulted in the determining of who should benefit? How will this sit with existing subsistence economies ${ }^{71}$ currently operating in remote Australia?

- The PBR itself, upon creation, becomes a commodity which can be traded. What protections will need to be considered to ensure the cultural rights to keystone species are not lost to Aboriginal peoples?

Finally, how will these and other important questions be asked? From whose understandings, world view and language will they be framed, developed and discussed? To ensure that 'improvements' such as those promoted through the development of PBRs align with both cultural imperatives and the effective protection of property rights in Western legal systems, engaging Aboriginal and non-Aboriginal peoples as co-researchers in partnerships where various knowledges, world views and languages can be considered and accorded respect will be critical. Finding solutions to PBR and other property rights issues in relation to bush foods and bush medicines will require more than just clever property rule design. Indeed, simply recognising that there is more to understand is where PAR can make a useful contribution to the process. This will require the establishment of deep relationships based on trust, and through which shared understandings can be developed. Such relationships are not

70 K A Seton and J J Bradley “"When you have no law you are nothing": Cane Toads, Social Consequences and Management Issues' (2004) 5(3) Asia Pacific Journal of Anthropology 205.

71 For an in-depth discussion of the value and importance of subsistence and hybrid economies in remote Australia see J C Altman 'Economic development and Indigenous Australia: Contestations over property, institutions and ideology' (2004) 48(3) The Australian Journal of Agricultural and Resource Economics 513; J C Altman 'Generating Finance for Indigenous Development: Economic Realities and Innovative options' (Centre for Aboriginal Economic Policy Research Working Paper No. 15/2002, The Australian National University, Canberra, 2002). 
about superficial consultation with select, disparate and loud voices, but rather require the meaningful, shared dialogues that occur over time, and that are based on respect for the value of different ways of knowing and doing, and which enable quiet voices to be heard.

Following Fals-Borda, ${ }^{72}$ understanding that value neutrality in social research is not always an ideal stance is especially meaningful and relevant in the bushfoods context. Deep involvement as participant rather than aloof academic observer $^{73}$ or external interventionist can help to build a rich picture of social situations that might otherwise be unattainable from more positivistic approaches. Thus, the trade-off between objectivity and collaborative learning in this intercultural space is extremely worthwhile. Indeed, I would argue that colonial understandings and manifestations of power and influence ${ }^{74}$ which currently privilege Western ways of knowing and doing can only be broken down through engaging in the kind of deep relationships inherent in participatory approaches. Otherwise, as the case study reported on here has highlighted, so much may simply be lost in translation.

\section{Acknowledgements}

This chapter has benefited significantly from critical comment provided by Susan Robinson, and I sincerely thank her.

The work reported here has been supported by funding from both the Northern Territory Natural Resources Management Board and the Australian Government Cooperative Research Centres Programme through the Desert Knowledge CRC. The views expressed herein do not necessarily represent the views of Desert Knowledge CRC or its participants.

72 Fals-Borda, above n 21.

73 Freire, above n 21.

74 Smith, above n 37. 